\title{
An Overview of Natural Extracts with Antioxidant Activity for the Improvement of the Oxidative Stability and Shelf Life of Edible Oils
}

\author{
Francesca Blasi $\mathbb{D}$ and Lina Cossignani *D \\ Department of Pharmaceutical Sciences, Food Science and Nutrition Section, University of Perugia, \\ 06126 Perugia, Italy; francesca.blasi@unipg.it \\ * Correspondence: lina.cossignani@unipg.it; Tel.: +39-075-5857959
}

Received: 1 July 2020; Accepted: 5 August 2020; Published: 8 August 2020

check for updates

\begin{abstract}
Many plant materials, such as fruits and vegetables as well as herbs and spices, represent valuable sources of antioxidants. In recent years, wastes from agriculture and food industrial processes have been shown to be interesting sources for bioactive compound recovery, strongly contributing to the circular economy. Nowadays, because of their possible adverse effects on human health, there is a tendency to replace synthetic antioxidants with natural compounds. This review attempts to critically summarize the current evidence on plant bioactives, extracted from food or waste, added to unsaturated vegetable oils, in order to obtain high added-value products and to ameliorate their oxidative stability and shelf life. The goal of this review is to demonstrate the current status of the research on edible oils added with natural plant bioactives, highlighting new approaches in the field of health-promoting foods.
\end{abstract}

Keywords: natural antioxidants; vegetable extracts; waste; edible oils; oxidative stability; shelf life

\section{Introduction}

Fats and oils, especially those containing a high level of unsaturated fatty acids, can undergo oxidation reactions with the formation of dangerous secondary products, above all after drastic heat treatments (i.e., frying) [1]. Numerous strategies can be used to increase oil oxidative stability during processing and storage, including: avoiding light, oxygen and high temperatures, changing the oil extraction conditions in order to increase the bioactive compound content, and adding antioxidant compounds [2].

Butylated hydroxytoluene (BHT) and butylated hydroxyanisole (BHA), but also tertiary butylhydroquinone (TBHQ), and propyl gallate are common examples of the synthetic antioxidants used in the vegetable oil industry to retard oxidation reactions [3]. Since some harmful effects for synthetic antioxidants have been reported $[4,5]$, international regulatory authorities have established limits to the amounts of synthetic antioxidants permitted in foods [6]. During the past decade, around the world, the preference of consumers for natural substitutes of synthetic additives is increasing $[5,6]$, mainly for ideational/emotional reasons [7]. This preference is mainly based on the idea that natural compounds are healthier than synthetics [8].

The incorporation of natural bioactives into traditional foods, in order to obtain new functional foods (i.e., oils, beverages, bakery and dairy products) is a rapidly growing market worldwide [9]. In the commercial segment of functional foods, the category of vegetable oils is the one with the fastest growth. As a result, recent studies have focused on the potential of phytochemicals as natural sources of health promoting compounds, useful for design and production of functional foods [10].

The objective of this overview is to highlight the strengths and weaknesses of the extraction processes and analytical characterization of bioactives from vegetable sources. This review focuses on 
enrichment procedures of edible oils with natural antioxidants in order to improve their oxidative stability, at room temperature (storage) or after heat treatment (frying). This paper reviewed the research papers on the above cited topic, focusing on the articles that have been published from 2016 .

\section{Extraction Methods of Natural Compounds with Antioxidant Activity}

Various solid-liquid extraction techniques have been reported for isolating plant antioxidants. Generally, the extraction methods can be divided into conventional and unconventional procedures [11,12]. The first are easy methods at high-solvent consumption, carried out with or without heat treatment. The second allow us to ameliorate the extraction efficiency and/or selectivity by using processing aids/energy inputs, including ultrasounds, microwaves, supercritical fluids, and others. The most important variables of the extraction methods, both conventional and unconventional ones, are solid/liquid ratio, solvent composition, time, and temperature [11,13]. It has been reported that differences regarding the values of total phenol content (TPC) and antioxidant activity of the extracts, obtained also from the same source, could be due to variety, growing conditions, climate, harvesting time, and processing conditions $[14,15]$.

Table 1 shows some examples of recent extraction procedures carried out in order to obtain natural extracts with antioxidant activity, for the presence of carotenoids and phenolics, subsequently used for the enrichment of vegetable oils.

Table 1. Examples of extraction procedures of natural antioxidants used for the enrichment of oils.

\begin{tabular}{|c|c|c|}
\hline Bioactives & Extraction Procedure & Reference \\
\hline Carotenoids & $\begin{array}{l}\text { Pre-treatment: Goji berry blended firstly with water and then shacked with methanol. } \\
\text { The recovered residue extracted by UAE using hexane/acetone mixture }(3: 2, v / v)\end{array}$ & {$[16,17]$} \\
\hline Carotenoids & $\begin{array}{l}\text { Pre-treatment: Tomato peel powder mixed with ethanol. } \\
\text { The recovered residue blended with acetone/hexane solution }(50: 50, v / v) \text { into } \\
\text { separatory funnel }\end{array}$ & [18] \\
\hline Carotenoids & $\begin{array}{l}\text { mango peel by supercritical } \mathrm{CO}_{2} \text { extraction (optimized conditions: } 25.0 \mathrm{MPa}, 60^{\circ} \mathrm{C} \\
\text { and ethanol, } 15 \% w / w)\end{array}$ & [19] \\
\hline Carotenoids & $\begin{array}{l}\text { tomato waste powder, in ten different vegetable oils, extracted by: (a) UAE ( } 35 \mathrm{kHz} \\
\left.\text { with } 480 \mathrm{~W} \text { ) at } 20^{\circ} \mathrm{C} \text { for } 50 \mathrm{~min} \text {; (b) MAE ( } 2450 \mathrm{MHz} \text { with } 700 \mathrm{~W}\right) \text { for } 5 \mathrm{~min} \text {; } \\
\text { (c) maceration at } 20^{\circ} \mathrm{C} \text { for } 7 \text { days }\end{array}$ & [20] \\
\hline Phenols & $\begin{array}{l}\text { olive leaf powder extracted with ethanol }(78 \%, v / v) \text { at r.t. for } 24 \mathrm{~h} \text {, for three times } \\
\text { olive fruit and olive pomace mixed with ethanol }(78 \%, v / v) \text { and stirred for } 30 \mathrm{~min}\end{array}$ & [21] \\
\hline Phenols & $\begin{array}{l}\text { olive leaf powder extracted with methanol/water }(80: 20, v / v) \text { at r.t. for } 12 \mathrm{~h} \text { under } \\
\text { agitation in dark place }\end{array}$ & [22] \\
\hline Phenols & $\begin{array}{l}\text { olive leaves extracted by MAE with methanol; while magnetic stirring, } 6 \text { min } \\
\text { irradiation was performed ( } 8 \mathrm{~s} \text { power on and } 15 \mathrm{~s} \text { power off in order to prevent } \\
\text { super-boiling of solvent). }\end{array}$ & [23] \\
\hline Phenols & $\begin{array}{l}\text { olive pomace homogenized with } 80 \% \text { methanol. After methanol removal, the } \\
\text { aqueous extract was used for SPE phenol separation by octadecyl silica cartridge and } \\
\text { eluting with methanol }\end{array}$ & [24] \\
\hline Phenols & $\begin{array}{l}\text { myrtle leaf powder extracted by MAE }(700 \mathrm{~W} \text { for } 1 \mathrm{~min}) \text { with ethanol/water } \\
(50: 50, v / v)\end{array}$ & [25] \\
\hline
\end{tabular}

According to the results of various papers, ethanol was found to be the best solvent for extracting phenolic compounds from plant materials [11,12], but sometimes ethanol or methanol with different proportion of water are also applied [12,21,24,26,27]. In addition, ethanol is classified with the GRAS status, so it is suitable for the recovery of nutraceuticals [28]. Classical solid-liquid extraction technique at room temperature was used to obtain phenols from fresh olive leaves using ethanol or methanol [11,12], or from olive fruit and olive pomace using hydroalcoholic mixtures [21,22]. Sordini et al. [24] extracted phenols from olive pomace homogenizing with $80 \%$ methanol, and then the aqueous extract was used for solid phase extraction (SPE) phenol separation by C18 cartridge and eluting with methanol. 
With regard to the extraction of carotenoids, a pre-treatment is necessary in order to remove all polar compounds and prepare the matrix for the effective extraction of carotenoids [16-18]. To this aim, Waqas et al. [18] used ethanol, while Blasi et al. [16] first used water and then methanol. Among conventional techniques, carotenoids from tomato peel powder have been extracted by using a classic mechanical mixing and then a separatory funnel to separate the non-polar layer, containing lipid materials, from the water-soluble fraction [18]. The acetone/hexane mixture, in different proportions $(50: 50, v / v$ or $3: 2, v / v)$, was the most used solution for carotenoid extraction [16-18].

Nowadays, sustainable and eco-friendly procedures are preferred to extract bioactives from aromatic herbs, fruits, and vegetables, for food enrichment [12,29]. Bio-based solvents (i.e., ethanol, ethyl acetate, ethyl lactate, and d-limonene) obtained from renewable sources, including plants, seaweeds, algae and food by-products, may become an environmentally favorable alternative [19]. Current research is addressed to the study of new green-extraction technology for the potential to overcome some limitations of conventional technologies. Among innovative methods, the ultrasoundassisted extraction (UAE) was used to obtain bioactives from several vegetable matrices, including berries $[16,17]$ and leaves $[13,26]$.

Alternatively, Nour et al. [20] performed a simultaneous extraction and enrichment with tomato carotenoids, by adding dried tomato waste into ten vegetable oils using UAE, microwave-assisted extraction (MAE) and maceration. They found that maceration proved to extract high amounts of carotenoids, and that UAE and MAE were effective in less time. MAE has been also used to extract phenolic compounds from olive [23] or myrtle [25] leaves, with methanol.

Among green extraction technologies, supercritical fluid extraction (SFE) showed numerous successful applications in the extraction of natural antioxidants from a wide range of matrices. For example, Sánchez-Camargo et al. [19] optimized the SFE extraction of carotenoids from mango peel, evaluating the effect of pressure, temperature, and co-solvent concentration. The advantage of using an experimental design is the possibility of easily optimizing the best conditions for the extraction of natural antioxidants to be used for oil enrichment. For this reason, it could valid to extend this approach, in order to optimize numerous factors affecting the enrichment of oils [30].

\section{Bioactive Compounds and Their Sources}

In the past, plant bioactive compounds were extensively used in the treatment of multifactorial diseases, and served as compounds of interest both in their natural form, but also as templates for synthetic modification.

Although the use of natural compounds is increasingly widespread, it is necessary to underline that a deep analytical characterization of the extracts is often not reported. Moreover, papers regarding the oil enrichment have not generally reported results on the biological activities of the added extracts. These critical aspects merit more investigations by scientists, taking into consideration the numerous variables affecting the plant material and the extraction procedures [11,15].

In fruits and vegetables, molecules of nutritional interest for the enrichment of traditional foods are mainly phenolic acids, flavonoids, carotenoids, and stilbenes in addition to other bioactive compounds (fibers, vitamins). In many cases, interesting extracts with antioxidant activity were obtained by using seed of fruits (i.e., tamarind, guava, citrus, pumpkin) [31]. Olive extracts are widely used to improve oxidative stability of oils. In fact, the phenolic extract of the olive fruit generally resulted in a good protection of the oils during storage and frying [21,24]. Among natural compounds, carotenoids represent another class of bioactives showing antioxidant capacity and numerous health benefits [32]. This class of molecules can be easily extracted from different types of vegetable food [16,17] or waste [18-20]. As an example, carotenoid extract from Lycium barbarum L., mainly containing zeaxanthin dipalmitate, was used to enrich samples of extra virgin olive oil (EVOO) [16,17], while all-trans- $\beta$-carotene and other carotenoids (9-cis- $\beta$-carotene and 13 -cis- $\beta$-carotene), identified in mango peel extract, were responsible for protective effect on sunflower oil (SFO) [19]. 
Nowadays, the main sources of natural antioxidants, used in ensuring oil stability during storage and food processing, are by-products from fruit and vegetable processing. In fact, plant parts, such as peel, kernel, leaf, flower and roots, considered waste products or by-products, are rich in antioxidant compounds which have shown beneficial properties for human health [12,26]. Composition, extraction, and application of bioactives from fruit processing waste (i.e., peel, pomace, and seed) were recently summarized by Banerjee et al. [31]. In leaves and vegetable wastes, molecules with antioxidant activity used to enrich traditional foods are mainly anthocyanidines, phenolic acids, flavonols, flavonones, carotenoids, and glycoside [31]. As an example, lycopene and carotenoids (phytofluene, $\beta$-carotene, cis-lycopene, lutein, cis- $\zeta$-carotene, $\zeta$-carotene, and $\gamma$-carotene) are the main bioactives from tomato peel [18]. An important part of olive mill and olive processing residues is represented by olive tree leaves [33]. Phenols from olive leaf extract (OLE) have been deeply analyzed, and it has been reported that OLE is a stronger antioxidant in respect to ascorbic acid. This result has been attributed to the synergistic effects among polyphenol compounds present in OLE [22]. Phenols from spinach and myrtle leaves have been also characterized, before addition to SFO and EVOO, respectively [25,34].

The use of herb extracts as natural food additives is a practical and interesting alternative, deriving from ancient traditions [35]. The current trend to add herb and spice extracts is also due to their health properties, thanks to the presence of bioactive compounds (e.g., carotenoids, phenolic acids, phenolic triterpenes, diterpenes and flavonoids) [36,37]. The most known aromatic plants, including oregano, rosemary, and basil, show many biologically active compounds, among which are phenolic compounds with numerous health properties (antimicrobial, antioxidant, antifungal, and anti-inflammatory activities). As an example, oregano extracts were used to enrich SFO [37] and canola oil [38], thyme extracts to enrich soybean oil (SBO) [37].

Table 2 shows some examples of vegetable extracts added to oils, together with the bioactives and the analytical procedure for their identification.

It can be highlighted that the main analytical procedures to identify bioactives are based on liquid-chromatography, in particular high-performance liquid chromatography (HPLC), equipped with suitable detection systems (Photodiode Array detector, PDA; Ultraviolet-Visible, UV-Vis). DAD has been used to analyzed phenolics from rambutan [39], spinach [34], and myrtle [25], but also carotenoids from goji [16,17], tomato [18] and mango [19]. However, hyphenation techniques, due to the coupling of more sophisticated detectors (e.g., mass spectrometer, MS, or nuclear magnetic resonance) has increased the capability of characterize also complex natural products. Nowadays, a MS detector coupled with PDA or UV-Vis is the most sought-after detection system employed for the HPLC analysis of herbal products $[16,17,22]$.

With regard to alternative sources of natural bioactive compounds, some minor categories with strong potential for the recovery of natural bioactive compounds attracted researcher attention. For example, in the last decades, the marine environment has proved to be one of the most interesting and rich sources of natural compounds with potential antioxidant activity, analogous to polyphenols derived from terrestrial plants [40]. Seaweed is an excellent source of powerful bioactive compounds (i.e., polyphenols, carotenoids, alkaloids, terpenes and tocopherol). As an example, Agregán et al. [40] assessed the antioxidant activity of Bifurcaria bifurcata aqueous extract (200, 400, 600, 800 and 1000 ppm) on the oxidative stability of canola oil ( $20 \mathrm{~mL})$ during storage $(4,8,12$ and 16 days). At the highest concentrations, significant decreases of primary and secondary oxidation products, with respect to the control, were obtained. Moreover, B. bifurcata extract was effective in retarding production of volatiles responsible for off-flavor during canola oil storage.

Moreover, a recent and interesting approach to improve oil stability regards the use of the outer layers of cereals, which are rich in phenolic antioxidants. As an example, Ajala and Ghavami [41] evaluated the effectiveness of black rice, millet and barley bran extracts (1000 ppm) against oxidative degradation of SBO $(100 \mathrm{~mL})$ during frying, and concluded that rice bran extract enriched oil can be used for frying without discarding or replenishing the oil. 
Table 2. Examples of some extracts added to oils, together with the identification of the bioactives.

\begin{tabular}{|c|c|c|}
\hline Type of Extract & Identification Bioactives & Reference \\
\hline $\begin{array}{l}\text { Goji (Lycium barbarum) } \\
\text { berries }\end{array}$ & $\begin{array}{l}\text { HPLC-DAD/MS system. } \\
\text { Carotenoids, lutein, and zeaxanthin dipalmitate were separated on C30 column } \\
(250 \times 4.6 \mathrm{~mm}, 5 \mu \mathrm{m}) \text {. } \\
\text { MP: (A) methanol and (B) methyl tert-butyl ether. Gradient elution. }\end{array}$ & {$[16,17]$} \\
\hline $\begin{array}{l}\text { Tomato (Solanum } \\
\text { lycopersicum) peel }\end{array}$ & $\begin{array}{l}\text { Lycopene was analyzed on an HPLC-PDA-UV/Vis system. } \\
\text { Phytofluene, } \beta \text {-carotene, cis-lycopene, lutein, cis- } \zeta \text {-carotene, } \zeta \text {-carotene, } \\
\text { and } \gamma \text {-carotene were separated on C18 column }(3.9 \times 150 \mathrm{~mm}) \text {. } \\
\text { MP: Methanol-ethyl acetic acid (54:46). }\end{array}$ & [18] \\
\hline $\begin{array}{c}\text { Olive (Olea europea) } \\
\text { leaves }\end{array}$ & $\begin{array}{l}\text { HPLC-UV/VIS-ESI-TOF-MS system. } \\
\text { Tyrosol, luteolin rutinoside, rutin, rutin isomers, 10-hydroxy-oleuropein, } \\
\text { luteolin glucoside, luteolin rutinoside isomers, verbascoside, luteolin glucoside } \\
\text { isomers, apigenin-7-O-glucoside, chrysoeriol-7-O-glucoside, oleuropein } \\
\text { glucoside, oleuropein, oleuropein isomer, oleoside, apigenin were separated on } \\
\text { an Agilent Eclipse Plus C18 column }(4.6 \times 150 \mathrm{~mm}, 1.8 \mu \mathrm{m}) \text {. } \\
\text { MP: (A) acetic acid }(0.5 \%) \text { and (B) acetonitrile. Gradient elution. }\end{array}$ & [22] \\
\hline $\begin{array}{l}\text { Rambutan (Nephelium } \\
\text { lappaceum) peel }\end{array}$ & $\begin{array}{l}\text { HPLC-DAD system. } \\
\text { Geraniin, ellagic acid, quercetin, and rutin were separated on Alltima C18 } \\
\text { column ( } 150 \mathrm{~mm} \times 4.6 \mathrm{~mm}, 5 \mu \mathrm{m}) \text {. } \\
\text { MP: (A) water/methanol }(95: 5) \text { and (B) water/methanol (5:95). Both A and B } \\
\text { solvents contained } 0.4 \% v / v \text { formic acid. Gradient elution. }\end{array}$ & [39] \\
\hline $\begin{array}{l}\text { Spinach (Spinacia } \\
\text { oleracea) leaves }\end{array}$ & $\begin{array}{l}\text { HPLC-DAD system. } \\
\text { ( } p \text {-hydroxybenzoic acid, } p \text {-coumaric acid, } \\
\text { isorhamnetin-3-(hydroxyferuloyl-glucoside)-7-glucoside, apigenin, } \\
\text { kaempferol-3-( }(p \text {-coumaroyl-diglucoside)-7-glucoside, } \\
\text { apigenin-2-O-pentoxide-8-hexoside, } \\
\text { quercetin-3-(sinapoyl-diglucoside)-7-glucoside, and } \\
\text { kaempferol-3-(sinapoyl-diglucoside)-7-glucoside) were separated on an Agilent } \\
\text { Zorbax Eclipse C18 column }(4.6 \times 250 \mathrm{~mm}, 5 \mu \mathrm{m}) \text {. } \\
\text { MP: (A) methanol/acetic acid/deionized water }(10: 2: 88) \text { and (B) methanol/acetic } \\
\text { acid/deionized water (90:2:8). Gradient elution. }\end{array}$ & [34] \\
\hline $\begin{array}{l}\text { Myrtle (Myrtus } \\
\text { communis) leaves }\end{array}$ & $\begin{array}{l}\text { HPLC-DAD and FLD system. } \\
\text { Galloylquinic acid, gallic acid, myricetin 3-O-galactoside, myricetin } \\
3 \text {-O-rhamnoside, and ellagic acid were separated on } 120 \text { ODS column } \\
(150 \times 4.6 \mathrm{~mm}, 5 \mu \mathrm{m}) \text {. } \\
\text { MP: (A) } 0.5 \% \text { acetic acid/0.1\% acetonitrile and (B) acetonitrile } / 0.5 \% \text { acetic acid. } \\
\text { Gradient elution. }\end{array}$ & [25] \\
\hline $\begin{array}{l}\text { Crude phenolic } \\
\text { concentrate from fresh } \\
\text { OMWW }\end{array}$ & $\begin{array}{l}\text { HPLC-DAD and FLD system. } \\
\text { 3,4-(dihydroxyphenyl)-ethanol, } p \text {-hydroxyphenyl-ethanol, verbascoside, } \\
\text { dialdehydic form of decarboxymethyl elenolic acid linked to hydroxytyrosol } \\
\text { were separated on a Spherisorb ODS- } 1 \text { column }(250 \times 4.6 \mathrm{~mm}, 5 \mu \mathrm{m}) \text {. } \\
\text { MP: (A) } 0.2 \% \text { acetic acid (pH 3.1)/water and (B) methanol. }\end{array}$ & [24] \\
\hline
\end{tabular}

\section{Application of Natural Antioxidants in the Improvement of Edible Oil Oxidative Stability}

Edible vegetable oils are generally rich in unsaturated fatty acids, which are prone to oxidation, the main cause of oil modification [42,43]. Such deterioration can be reduced using suitable lipophilic or hydrophilic antioxidants. Sometimes, oil-in-water $(\mathrm{O} / \mathrm{W})$ and water-in-oil $(\mathrm{W} / \mathrm{O})$ emulsions have been used [23].

The main edible added-oils were refined oils, including SBO, SFO, and flaxseed oils, but also virgin oils such as EVOO.

Table 3 summarizes the main studies regarding oils enriched with natural antioxidants, with details regarding the type of extract, the quantity of extract added to oils, and some chemical-analytical parameters for the evaluation of the thermal oxidative stability of enriched oils, published from 2016. 
Table 3. Natural antioxidants added to oils: Type of extract, oil enrichment and thermal oxidative stability.

\begin{tabular}{|c|c|c|c|}
\hline Type of Extract & Enriched-Oils and Control & Thermal Oxidative Stability & Reference \\
\hline goji berry extract & $\begin{array}{l}\text { EVOOCar: EVOO added with carotenoid } \\
\text { extract }(1.5 \mathrm{mg} / 100 \mathrm{~g} \text { oil) Control: } \\
\text { Unenriched EVOO }\end{array}$ & 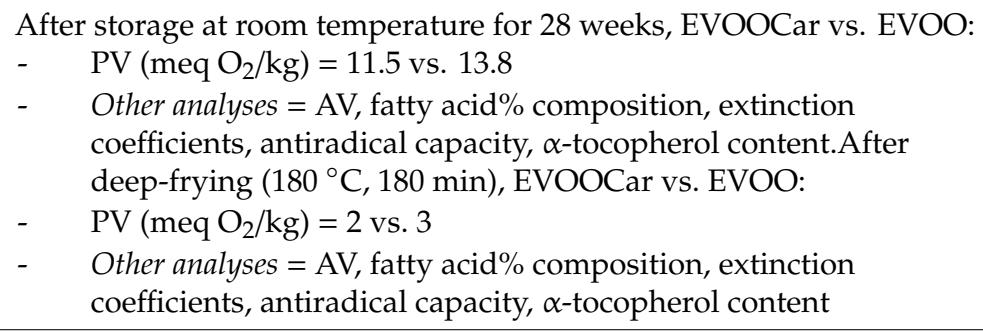 & {$[16,17]$} \\
\hline tomato waste extract & $\begin{array}{l}\text { Dried tomato waste extract at } 5 \%(w / v) \text { in oils. } \\
\text { Control: unenriched oils }(S F O, \text { unrefined corn } \\
\text { oil, refined rapeseed oil, EVOO, olive pomace oil, } \\
\text { SBO, refined SFO, peanut oil, rice oil, grape seed) }\end{array}$ & 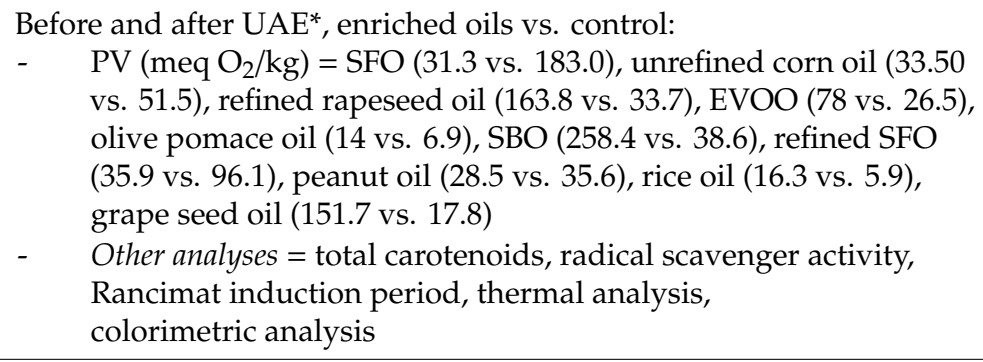 & [20] \\
\hline OLE; OFE; OPE & $\begin{array}{l}200 \text { mg TPC (OLE, OFE, OPE) per kg SFO. } \\
\text { Control: Unenriched SFO }\end{array}$ & $\begin{array}{l}\text { After seven frying (each, every } 6 \mathrm{~h}) \text { at } 180{ }^{\circ} \mathrm{C}: \\
-\quad \mathrm{PV}\left(\mathrm{meq} \mathrm{O}_{2} / \mathrm{kg}\right)=\mathrm{SFO}(76.96)>\mathrm{SFO}+\mathrm{OPE}(60.76)>\mathrm{SFO}+\mathrm{OLE} \\
(47.20)>\mathrm{SFO}+\mathrm{OFE}(37.11) \\
-\quad \text { Other analyses = FFA, extinction coefficients }(\mathrm{K} 232, \mathrm{~K} 270), \mathrm{DPPH} \%\end{array}$ & {$[21]$} \\
\hline OLE & $\begin{array}{l}\text { SBO added with } 200 \text { ppm, } 500 \text { ppm, } 1000 \\
\text { ppm, } 1500 \text { ppm OLE Control: Unenriched } \\
\text { SBO, TBHQ (200 ppm) }\end{array}$ & $\begin{array}{l}\text { At the end of storage }\left(60^{\circ} \mathrm{C}, 21 \text { days): }\right. \\
-\quad p-A V \approx 23 \text { SBO OLE } 1000, \text { SBO OLE } 1500 \text { (11 SBO TBHQ) } \\
-\quad \quad \text { oil degradation percentage = 3.08\% SBO OLE 1000; 0.16\% SBO } \\
\text { OLE } 1500 \text { (2.09\% TBHQ 200) } \\
\text { - } 18: 1, \text { trans: Nd SBO OLE 1000; } 1.56 \text { SBO OLE 1500; } 1.65 \text { TBHQ } \\
\text { 200 - Other analyses: Rancimat analysis, accelerated oxidation } \\
\text { test (Schaal Oven test), FA } \% \text { composition }\end{array}$ & [22] \\
\hline
\end{tabular}


Table 3. Cont.

\begin{tabular}{|c|c|c|c|}
\hline Type of Extract & Enriched-Oils and Control & Thermal Oxidative Stability & Reference \\
\hline OLE & $\begin{array}{l}\text { SBO added with 100, } 200 \text { and } 300 \mathrm{mg} / \mathrm{kg} \\
\text { OLE (non-encapsulated, OLEN, OLEW, } \\
\text { OLENWP) Control: TBHQ (100 to } 200 \mathrm{mg} / \mathrm{kg})\end{array}$ & $\begin{array}{l}\text { At the end of storage }\left(55^{\circ} \mathrm{C}, 20 \text { days): }\right. \\
\text { - } \quad \text { PV }\left(\mathrm{meq} \mathrm{O}_{2} / \mathrm{kg}\right)=37.4,35.6,28.2 \text { for SBO with non-encapsulated } \\
\text { OLE } 100,200 \text { and } 300 ; 26.5,22.3,20.6 \text { for SBO with } 100,200 \text { and } \\
\text { 300 OLEN; } 22.6,19,14.4 \text { for SBO with OLEW; } 18.05,14.6 \text {, and } \\
\text { 12.2 for SBO with OLEWP } \\
\text { - Other analyses = Rancimat induction period, TBA value }\end{array}$ & [23] \\
\hline $\begin{array}{l}\text { Extract rambutan } \\
\text { (Nephelium lappaceum) } \\
\text { peel powder (ERPP) }\end{array}$ & $\begin{array}{l}\text { refined SBO }(30 \mathrm{~mL}) \text { mixed with ERPP } \\
\text { solution }(1 \mathrm{~mL}) \text {, leading to a final } \\
\text { concentration of } 10 \mu \mathrm{g} \text { GAE/g, } 100 \mu \mathrm{g} \mathrm{GAE} / \mathrm{g} \\
\text { and } 1000 \mu \mathrm{g} \text { GAE/g of oil (RBP10, RBP100, } \\
\text { RBP1000) Control: TBHQ (100 } \mu \mathrm{g} / \mathrm{g} \text { oil })\end{array}$ & 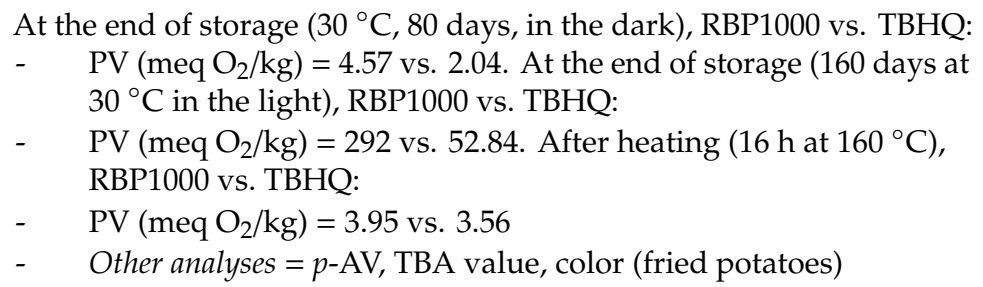 & [39] \\
\hline $\begin{array}{l}\text { crude phenolic } \\
\text { concentrate from } \\
\text { fresh OMWW }\end{array}$ & $\begin{array}{l}\text { The extract was mixed into ROO }(1.6 \mathrm{~kg} \\
\text { each) to reach final phenolic compound } \\
\text { concentrations of } 400 \text { (PE1) and } 600 \mathrm{mg} / \mathrm{kg} \\
\text { (PE2) (sum of identified phenols). Control: } \\
\text { BHT }(100 \mathrm{mg} / \mathrm{kg})\end{array}$ & $\begin{array}{l}\text { After frying }\left(180^{\circ} \mathrm{C}, 6 \mathrm{~h}\right): \\
-\quad \mathrm{PV}\left(\mathrm{meq} \mathrm{O}_{2} / \mathrm{kg}\right)=2.41 \text { (ROO-PE1) } 2.11 \text { (ROO-PE2) vs. } \\
3.46 \text { control } \\
\text { Other analyses }=\mathrm{AV}, \mathrm{FA} \% \text { composition, FFA, extinction } \\
\text { coefficients }(\mathrm{K} 232, \mathrm{~K} 270), \alpha \text {-tocopherol content, volatile } \\
\text { compounds (acrolein, hexanal), chlorogenic acid concentration } \\
\text { (French fry potatoes) }\end{array}$ & [24] \\
\hline OMWW & $\begin{array}{l}10 \mathrm{~mL} \text { of oil (VOO, } 7 \%+\text { refined olive oil } \\
\text { ROO, } 93 \%) \text { mixed with } 10 \mathrm{~mL} \text { WWA (PE-A) } \\
\text { or WWB (PE-B). Control: VOO }(7 \%)+ \\
\text { ROO }(93 \%)\end{array}$ & $\begin{array}{l}\text { PE-A and PE-B vs. control: PV }\left(\text { meq } \mathrm{O}_{2} / \mathrm{kg}\right)=5.47 \text { vs. } 5.46 \\
-\quad \text { Other analyses }=\text { AV, FFA, extinction coefficients }(\mathrm{K} 225, \mathrm{~K} 270), \Delta \mathrm{K} \text {, } \\
\text { bitter index, TPC, TEAC, endothelial cell viability }\end{array}$ & [44] \\
\hline
\end{tabular}

${ }^{*}$ UAE conditions are described in Table 1, together with MAE and maceration conditions. 


\subsection{Soybean Oil}

Soybean production represents more than $50 \%$ of worldwide vegetable oil production [45]. The main fatty acids of SBO are linoleic (C18: $2 \omega 6)$ and oleic (C18: $1 \omega 9)$ acids.

Recently, to improve SBO stability against oxidation, Zahran and Najafi [22] used phenolic compounds extracted from olive leaves, a good source of natural antioxidants [21,23]. The oil samples containing OLE exhibited lower peroxide value (PV) with respect to the control (unenriched SBO), while higher PV compared to the sample containing TBHQ (200 ppm). The oil samples containing different amounts of OLE (1000 and $1500 \mathrm{ppm}$ ) showed a significant $(p<0.05)$ lower level of secondary products compared to the control (without OLE), but less effective compared to TBHQ.

The addition of OLE to SBO has been also proposed by Mohammadi et al. [23]. At the first stage, nano-encapsulation of OLE was performed by preparation of W/O nano-emulsions. Double layer encapsulation of initial $\mathrm{W} / \mathrm{O}$ nanoemulsions with biopolymers resulted in $\mathrm{W} / \mathrm{O} / \mathrm{W}$ double emulsions. They applied these new formulations to improve antioxidant activity of SBO, obtaining increased solubility of phenolic compounds and their controlled release. In particular, they concluded that oxidation protection offered by encapsulated OLE with pectin-whey protein concentrate was comparable to TBHQ with a better controlled release of phenolic compounds. The main disadvantage was that thermal stability of oil samples containing encapsulated forms of OLE was lower than the unencapsulated form. These results confirm that nano-technologies could be useful in order to protect and increase some properties of bioactive compounds (i.e., solubility, antioxidant activity, and stability).

Phuong et al. [39] carried out the enrichement of SBO with an extract from rambutan (Nephelium lappaceum L.) fruit peel, and obtained interesting results after storage (in the dark for 160 days: under light at $30^{\circ} \mathrm{C}$ or in the dark at $4{ }^{\circ} \mathrm{C}$ ) and deep frying (at $160{ }^{\circ} \mathrm{C}$ for $150 \mathrm{~min}$ ). In fact, the addition of the extract of rambutan, at $1000 \mu \mathrm{g}$ gallic acid equivalent (GAE)/g of oil, retarded the lipid oxidation process, as well as TBHQ (100 $\mu \mathrm{g} / \mathrm{g}$ of oil), obtaining potatoes fried in the fortified oil with the lowest levels of thiobarbituric acid (TBA) reactive substances.

In another study, Manzano et al. [30] used a factorial design to determine the optimal conditions for the use of polyphenols $(0 \%, 0.02 \%$, and $0.04 \% \mathrm{~m} / \mathrm{m})$, extracted from Theobroma cacao, as antioxidant to add to refined SBO samples. They found that higher concentrations $(0.04 \% \mathrm{~m} / \mathrm{m})$ of polyphenols retarded the generation of free fatty acids and $\mathrm{PV}$, and increased the antioxidant activity, determined by DPPH (2,2-diphenyl-1-picrylhydrazyl) assay after frying (20 times). Moreover, it was observed that the addition of polyphenols did not affect the coloration of the oil samples, aspect generally overlooked in recent published works [30].

SBO was also added with Cressa cretica [27] and Thymus vulgaris [37] leaf extracts. To counteract the oxidation process of SBO, Afshari et al. showed that C. cretica ethanolic extract (1000 ppm) was effective to inhibit SBO deterioration (based on PV and TBA values), successfully replacing BHT [27]. The oxidative stability of SBO supplemented with ethanolic extracts of thyme $(0.07 \%)$ was improved, in comparison with the same oil without the addition of herbal plant extracts or with the addition of BHA at $0.01 \%$ [37].

\subsection{Sunflower Oils}

Another conventional oilseed that yields oils for edible purposes is sunflower [45]. In general, the content of oleic and linoleic acids in SFO represents between 85 to $90 \%$ of total fatty acid, making it unstable for oxidative processes $[42,43]$.

As just reported for SBO, OLE is one of the most used extracts to enrich various refined oils, including SFO. For example, Atalay and Inanc [21] enriched SFO with ethanolic OLE, but also with extracts from olive fruits, and olive pomace (each separately). All enriched oils, after the deep-frying process, exhibited higher percentages of DPPH radical scavenging activity, and so more antioxidant efficiency, with respect to the control oil (non-added SFO). They concluded that phenolic extract of the olive fruit resulted in better protection of the oil during frying, with respect to the other two phenolic sources (leaves and pomace), even if the potential use of these agricultural by-products represents 
an important economic advantage. Methanolic extracts of olive pomace and olive mill wastewater (OMWW) were also studied by Günal-Köroğlu et al. [46] to enhance the stability of refined SFO during deep-frying $\left(180^{\circ} \mathrm{C}\right)$. They found that OMWW extract $(1 \mathrm{mg} / \mathrm{g})$ had higher phenolic content if compared to olive pomace extract (OPE). Moreover, the same authors observed that the addition of OMWW and olive pomace extracts combined with soy lecithin showed better antioxidant activity than individual extracts [46].

Recently, Zeb and Ullah [34] added methanolic extract of spinach (Spinacia oleracea), in different ratios (i.e., 2, 4, and $8 \mathrm{~g} / 100 \mathrm{~g}$ of oil), to SFO to assess its suitability during thermal stress (open frying for $1 \mathrm{~h}$ at $160{ }^{\circ} \mathrm{C}$ ) and concluded that it may serve as a good natural stabilizer in food frying, due to the presence of the major phenolic compounds (Table 2). This is one of the few papers showing the chromatographic characterization of enriched SFO samples, in addition to classical lipid oxidation parameters (PV, $p$-anisidine and TBA values) and classical antioxidant activity assay (TPC, DPPH and radical scavenging activity). Previously, the same researchers studied the effects of high temperature frying $\left(250{ }^{\circ} \mathrm{C}\right)$ on bioactives of spinach leaves, processed for different times (15-60 min), highlighting that spinach leaves increased the stability of fried SFO [47].

The oxidative stability of SFO samples enriched with ethanolic extracts of oregano (0.07\%) was improved compared to SFO without the addition of herbal plant extracts, or with the addition of BHA $(0.01 \%)$ [37]. Differently from other studies, the assessment of oxidative stability of added oils, and also the efficiency of herbal extracts, were performed by differential scanning calorimetry, in addition to the classical determination of PV and acidity values, and FA composition [37].

Hussain et al. [48] studied the efficacy of methanolic extracts of sesame seeds (500-1000 $\mu \mathrm{L} / 100 \mathrm{~mL}$ of oil) in stabilizing SFO during storage. They found that, at the highest concentration, the SFO stabilization was comparable to that of SFO added with BHT at its legal limit (200 ppm). This result was due to the improving of its hydrolytic stability, inhibiting of the lipid oxidation, and reducing the loss of polyunsaturated fatty acids (PUFA). The novelty of this paper was the evaluation of oxidative stability of food products (muffin) containing enriched SFO, also considering sensory evaluation (color, taste, texture, flavor, and acceptability). This aspect is important to consider in the early stages of designing a product that can potentially be placed on the market.

Sánchez-Camargo et al. [19] enriched refined, bleached, and deodorized sunflower oils with extract from mango peel, obtained by SFE. They reported that the extract was able to protect SFO from lipid oxidation, observing higher effectiveness of the extract obtained by SFE than pure all-trans- $\beta$-carotene. This conclusion might be explained by the synergistic effect of the all-trans- $\beta$-carotene with the other carotenoids present in the extract. Furthermore, based on TPC values, other compounds different from carotenoids (for instance, phenolic compounds) might contribute to such a positive effect.

Carotenoids from tomato (Solanum lycopersicum) peel have been also added as natural antioxidants and colorants in SFO [18]. The SFO containing from 50 to $200 \mathrm{mg} / \mathrm{kg}$ carotenoids (compounds indicated in Table 2) showed higher antioxidant activity in comparison to oil added with BHT (200 mg/kg).

\subsection{Olive Oils (EVOO, Refined)}

EVOO is the main fat of the Mediterranean diet, widely produced and consumed in Mediterranean countries. Due to the high content of oleic acid, EVOO shows higher stability against oxidation and heating processes, in respect to other edible oils (i.e., SBO, SFO) [49].

As reported for $\mathrm{SBO}$, polyphenols recovered from olive are commonly used as natural preservatives. Recently, Sordini et al. [24] reported that crude phenolic concentrate from fresh OMWW (compounds indicated in Table 2) significantly reduced the $\alpha$-tocopherol oxidation, and the formation of unwanted compounds. Moreover, enriched SBO preserved the sensory and nutritional value of French fries, according to its concentration $(400 \mathrm{mg} / \mathrm{kg}$ and $600 \mathrm{mg} / \mathrm{kg})$, during oil thermal treatment. Venturi et al. [44] also developed an olive oil enriched with phenolic compounds extracted from OMWW, confirming that wastewater collected during oil processing could be considered as a valid bioactive compound 
source. They observed that the two major olive oil phenols (tyrosol and hydroxytyrosol) showed antioxidant activity in an in vitro model of endothelial cells, preserving them from oxidative damage.

Galanakis et al. [50] tested the efficacy of polyphenols (recovered from OMWW) for the prevention of oil (EVOO and refined olive kernel) oxidation. However, in this work, the researchers did not extract the bioactives, but purchased a natural product containing $10 \%$ olive polyphenols per weight (50\% of which is hydroxytyrosol) and $50 \%$ maltodextrin as powder carrier. They concluded that olive polyphenols $\left(500 \mathrm{mg} / \mathrm{L}\right.$ and $3000 \mathrm{mg} / \mathrm{L}$ ) reduced the oxidation of heated oils (oven at $100{ }^{\circ} \mathrm{C}$ for $30 \mathrm{~min}$ and at $160{ }^{\circ} \mathrm{C}$ for $\left.120 \mathrm{~min}\right)$, while ascorbic acid $(2000 \mathrm{mg} / \mathrm{L}$ and $3000 \mathrm{mg} / \mathrm{L}$ ) was more efficient in the case of olive kernel oil. In contrast, tocopherol formulations showed low effectiveness against various oxidation indexes (i.e., PV, p-anisidine values, total polar components, "totox" index and extinction coefficient, K270).

As regards the use of waste, Dairi et al. [25] studied the enrichment of EVOO by myrtle phenolic leaf extracts. They reported an improved antioxidant activity of the final product (better than EVOO added with BHT) due to the increased scavenging activity towards free radicals. No additional loss effect against DPPH radical by adding $\alpha$-tocopherol was observed. Interestingly, this paper reported the effect of the enriched EVOO on peroxidation of a phospholipid aqueous dispersion model under simulated gastrointestinal conditions. Dairi et al. [25] highlighted that phenolic compounds may act against free radical attack, through several mechanisms of action. Because various kinds of interactions between antioxidants in a complex mixture may occur, in order to produce a healthy supplement or functional food, it is important to choose the best combination of antioxidants. Interestingly, another aspect to take into consideration is the simulative digestion (bioabsorption, bioavailability). This aspect is less extensively studied, and thus more research is necessary in this field.

It has been reported that EVOO addition with L. barbarum berry extract, rich in carotenoids, might represent a valuable strategy to improve oil stability while providing health-promoting compounds, both during frying at $180{ }^{\circ} \mathrm{C}$ for $180 \mathrm{~min}$ [16], and for long-term storage of 28 weeks at room temperature [17]. Recently, it has been reported that the consumption of lycopene-enriched EVOO showed additional health properties with respect to non-enriched VOO [51].

\subsection{Miscellaneous}

In addition to the oils reported in the previous paragraphs, many other oils are currently used as foods and ingredients.

The widest overview of vegetable oils, enriched with carotenoids originating from dry tomato waste, has been reported by Nour et al. [20]. They considered commercial SFO, unrefined corn oil, refined rapeseed oil, EVOO, olive pomace oil, $\mathrm{SBO}$, refined SFO, rice oil, peanut oil, and grapeseed oil samples. The authors reported that the extraction of carotenoids from dry tomato waste improved the oxidative and thermal stability only of some oils (unrefined corn, refined SFO and peanut oils), while in the other ones it caused an increase in the PV and a decrease in the induction time.

Among the least used oils are flaxseed, canola, and hazelnut oils. Flaxseed oil (FSO) is a rich source of $\alpha$-linolenic acid (C18: $3 \omega 3$ ), and oxidative deterioration is the major issue limiting its use. Recently, Roschel et al. [52] reported that a hydrophilic mixture (sinapic, ascorbic, and citric acids) improved the oxidative stability of FSO (crude or stripped) better than lipophilic mixture ( $\alpha$-tocopherol, ascorbyl palmitate, and citric acid). Moreover, hydrophilic mixture presented efficacy comparable to TBHQ, in preventing the formation of primary and secondary oxidation products. Mohanan et al. [53] also evaluated the effect of natural antioxidants of different polarity (tannic acid, $\alpha$-tocopherol, and ascorbyl palmitate) to improve the stability of FSO during long term storage and accelerated oxidation. Ascorbyl palmitate gave an antioxidant protection comparable to TBHQ, while tannic acid was not able to prevent lipid oxidation.

Canola oil is considered an important source of oleic acid and also PUFA, such as linoleic and $\alpha$-linolenic acids. Among various herbs (basil, rosemary, oregano, and sage), Boroski et al. [38] reported that ethanolic extract of oregano was able to prevent peroxide formation, but no differences were 
observed regarding canola $\mathrm{FA} \%$ composition, up to 10 days of storage at $60{ }^{\circ} \mathrm{C}$ with or without antioxidants. Their results agree with the polar paradox theory, describing that polar compounds are more effective in nonpolar media. In addition, they evaluated by sensorial analysis samples prepared with ethanolic oregano extract at $1.0 \%(w / v)$, showing a potential market for oils enriched with natural phenolic compounds. A sensory evaluation and consumer acceptability of the new product (enriched-oil) are helpful in meeting end-user expectations and ultimately getting large market share. The frying stability of canola oil was evaluated after addition of Teucrium polium extract, obtained by UAE [54]. The lower degradation of enriched-oil was due to the presence of tocopherols, phenolics, flavonoids, and tannins in the extract. Color changes were also evaluated, but no sensory analysis was performed.

Gülmez et al. [55] evaluated the oxidative stability of hazelnut oil treated with natural (gallic acid and/or $\beta$-carotene) antioxidants, compared with synthetic ones (TBHQ and BHT). They concluded that, in the dark, during 80 days in ambient conditions, gallic acid enhanced the shelf-life of the enriched-oil nearly 3 times over the untreated sample. In addition, total phenols increased by $77 \%$, improving the quality indicators and bioactivity properties. The main limit of this research is that hazelnut oil is less used and rarely commercially available with respect to the other oils, but despite this, it is important to have a wide overview of all kinds of enriched oils.

\section{Conclusions}

Based on many researches performed in the past decades, there is increasing evidence that natural antioxidants can be obtained from low cost resources using eco-friendly, unconventional extraction methods. It has been also reported that edible oils, enriched with natural antioxidants, showed comparable or higher antioxidant activity and thermal stability than oils added with synthetic ones. In this context, it is important to choose the best concentration and combination of antioxidants when designing functional foods, examining potential synergistic effects of natural antioxidants.

The main weakness of many studies is the absence of a deep analytical characterization of extracts. In fact, this review highlights the fact that most papers on oil enrichment did not take into consideration the necessity to have a reliable analytical approach to characterize the bioactives responsible for an ameliorating of oxidative stability. Various chemical compounds have been identified and isolated from different parts of plants, but no report on the contents of anti-nutritional factors/harmful constituents of these natural extracts is available. The quantification and identification of anti-nutritional factors may help the nutritionists and scientists to take decisions on the use and dose of extracts. Only a few papers have reported the most active antioxidant compounds of the extracts, while the main researches reported the traditional oil analysis, sometimes without evaluating the conjugated diene/triene content, reliable indicators of secondary lipid oxidation products, whose degradation causes off-color and off-flavor, affecting the quality characteristics of the oil.

In the context of enriched-oil design, it is important to consider the possibility, and sometimes the necessity, to apply some encapsulation techniques in order to protect the health properties of bioactives. Moreover, it is important to take into consideration the use of inexpensive and eco-friendly extraction processes, thinking about a further scale-up at industry level. In addition, further nutritional, biochemical-physiological and clinical studies are needed to evaluate the bioavailability and the interactions of the bioactive compounds present in enriched-oil, after consumption, under intestinal conditions both in humans and in animal models.

A multidisciplinary approach would be desirable for improving outcomes in this interesting sector of the food chemistry, aimed at the production of functional foods. In conclusion, more work is needed to expand the market for these natural compounds in food formulations.

Author Contributions: F.B. and L.C.: Conceptualization, investigation, formal analysis, writing—original draft, writing-review and editing. All authors have read and agreed to the published version of the manuscript.

Funding: This research received no external funding. 
Conflicts of Interest: The authors declare no conflict of interest.

\section{Abbreviations}

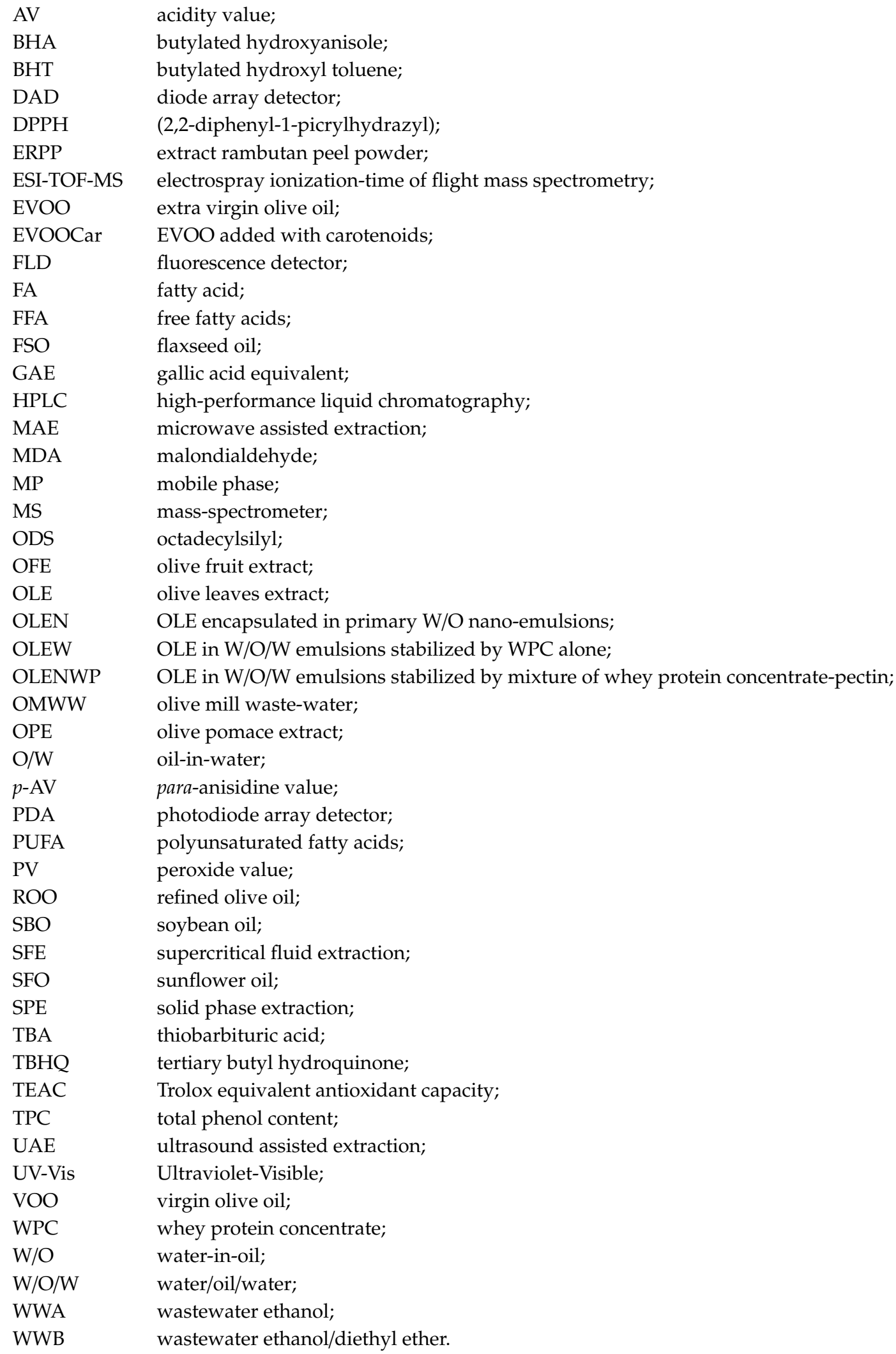




\section{References}

1. Grootveld, M.; Percival, B.C.; Leenders, J.; Wilson, P.B. Potential adverse public health effects afforded by the ingestion of dietary lipid oxidation product toxins: Significance of fried food sources. Nutrients 2020, $12,974$. [CrossRef] [PubMed]

2. Grosshagauer, S.; Steinschaden, R.; Pignittera, M. Strategies to increase the oxidative stability of cold pressed oils. LWT Food Sci. Technol. 2019, 106, 72-77. [CrossRef]

3. Carocho, M.; Ferreira, I.C.F.R. A review on antioxidants, prooxidants and related controversy: Natural and synthetic compounds, screening and analysis methodologies and future perspectives. Food Chem. Toxicol. 2013, 51, 15-25. [CrossRef] [PubMed]

4. EFSA. Scientific Opinion on the re-evaluation of butylated hydroxyanisole-BHA (E 320) as a food additive. EFSA J. 2011, 9, 2392. [CrossRef]

5. EFSA. Scientific Opinion on the re-evaluation of butylated hydroxytoluene BHT (E 321) as a food additive. EFSA J. 2012, 10, 2588. [CrossRef]

6. European Commission. Commission Regulation (EU) No 1129/2011 of 11 November 2011 amending Annex II to Regulation (EC) No 1333/2008 of the European Parliament and of the Council by establishing a Union list of food additives. Off. J. Eur. Union 2011, 295, 1-177.

7. Scott, S.E.; Rozin, P.; Small, D.A. Consumers prefer "natural" more for preventatives than for curatives. J. Consum. Res. 2020, ucaa034. [CrossRef]

8. Rozin, P.; Mark Spranca, M.; Krieger, Z.; Neuhaus, R.; Surillo, D.; Swerdlin, A.; Wood, K. Preference for natural: Instrumental and ideational/moral motivations, and the contrast between foods and medicines. Appetite 2004, 43, 147-154. [CrossRef]

9. Lourenço, S.C.; Moldão-Martins, M.; Alves, V.D. Antioxidants of natural plant origins: From sources to food industry applications. Molecules 2019, 24, 4132. [CrossRef]

10. Da Silva, B.V.; Barreira, J.C.M.; Oliveira, M.B.P.P. Natural phytochemicals and probiotics as bioactive ingredients for functional foods: Extraction, biochemistry and protected-delivery technologies. Trends Food Sci. Technol. 2016, 50, 144-158. [CrossRef]

11. Giacometti, J.; Kovačević, D.B.; Putnik, P.; Gabrić, D.; Bilušić, T.; Krešić, G.; Stulić, V.; Barba, F.J.; Chemat, F.; Barbosa-Cánovas, G.; et al. Extraction of bioactive compounds and essential oils from Mediterranean herbs by conventional and green innovative techniques: A review. Food Res. Int. 2018, 113, 245-262. [CrossRef] [PubMed]

12. Rocchetti, G.; Blasi, F.; Montesano, D.; Ghisoni, S.; Marcotullio, M.C.; Sabatini, S.; Cossignani, L.; Lucin, L. Impact of conventional/non-conventional extraction methods on the untargeted phenolic profile of Moringa oleifera leaves. Food Res. Int. 2019, 115, 319-327. [CrossRef] [PubMed]

13. Rocchetti, G.; Pagnossa, J.P.; Blasi, F.; Cossignani, L.; Piccoli, R.H.; Zengin, G.; Montesano, D.; Cocconcelli, P.S.; Lucini, L. Phenolic profiling and in vitro bioactivity of Moringa oleifera leaves as affected by different extraction solvents. Food Res. Int. 2020, 127, 108712. [CrossRef] [PubMed]

14. Blasi, F.; Urbani, E.; Simonetti, M.S.; Chiesi, C.; Cossignani, L. Seasonal variations in antioxidant compounds of Olea europaea leaves collected from different Italian cultivars. J. Appl. Bot. Food Qual. 2016, 89, $202-207$. [CrossRef]

15. Pollini, L.; Rocchi, R.; Cossignani, L.; Mañes, J.; Compagnone, D.; Blasi, F. Phenol profiling and nutraceutical potential of Lycium spp. leaf extracts obtained with ultrasound and microwave assisted techniques. Antioxidants 2019, 8, 260. [CrossRef]

16. Blasi, F.; Rocchetti, G.; Montesano, D.; Lucini, L.; Chiodelli, G.; Ghisoni, S.; Baccolo, G.; Simonetti, M.S.; Cossignani, L. Changes in extra-virgin olive oil added with Lycium barbarum L. carotenoids during frying: Chemical analyses and metabolomic approach. Food Res. Int. 2018, 105, 507-516. [CrossRef]

17. Montesano, D.; Rocchetti, G.; Cossignani, L.; Senizza, B.; Pollini, L.; Lucini, L.; Blasi, F. Untargeted metabolomics to evaluate the stability of extra-virgin olive oil with added Lycium barbarum carotenoids during storage. Foods 2019, 8, 179. [CrossRef]

18. Waqas, M.; Shad, A.A.; Bashir, O.; Iqbal, M. Extraction and utilization of tomato carotenoids as antioxidant and natural colorants in sunflower oil and spaghetti. Sarhad J. Agric. 2017, 33, 248-254. [CrossRef] 
19. Sánchez-Camargo, A.P.; Gutiérrez, L.F.; Vargas, S.M.; Martinez-Correa, H.A.; Parada-Alfonso, F.; Narváez-Cuenca, C.E. Valorisation of mango peel: Proximate composition, supercritical fluid extraction of carotenoids, and application as an antioxidant additive for an edible oil. J. Supercrit. Fluids 2019, 152, 104574. [CrossRef]

20. Nour, V.; Corbu, A.R.; Rotaru, P.; Karageorgou, I.; Lalas, S. Effect of carotenoids, extracted from dry tomato waste, on the stability and characteristics of various vegetable oils. Grasas Aceites 2018, 69, e238. [CrossRef]

21. Atalay, A.B.; Inanc, A.L. Stability of sunflower oil enriched with olive phenolics in deep frying condition. JAFAG 2018, 35, 152-163. [CrossRef]

22. Zahran, H.A.; Najafi, Z. Enhanced stability of refined soybean oil enriched with phenolic compounds of olive leaves. Egypt. J. Chem. 2020, 63, 215-224. [CrossRef]

23. Mohammadi, A.; Jafari, S.M.; Esfanjani, A.F.; Akhavan, S. Application of nano-encapsulated olive leaf extract in controlling the oxidative stability of soybean oil. Food Chem. 2016, 190, 513-519. [CrossRef] [PubMed]

24. Sordini, B.; Veneziani, G.; Servili, M.; Esposto, S.; Selvaggini, R.; Lorefice, A.; Taticchi, A. A quanti-qualitative study of a phenolic extract as a natural antioxidant in the frying processes. Food Chem. 2019, 279, 426-434. [CrossRef]

25. Dairi, S.; Carbonneau, M.A.; Galeano-Diaz, T.; Remini, H.; Dahmoune, F.; Aoun, O.; Belbahi, A.; Lauret, C.; Cristol, J.P.; Madan, K. Antioxidant effects of extra virgin olive oil enriched by myrtle phenolic extracts on iron-mediated lipid peroxidation under intestinal conditions model. Food Chem. 2017, 237, 297-304. [CrossRef]

26. Pollini, L.; Tringaniello, C.; Ianni, F.; Blasi, F.; Manes, J.; Cossignani, L. Impact of ultrasound extraction parameters on the antioxidant properties of Moringa oleifera leaves. Antioxidants 2020, 9, 277. [CrossRef]

27. Afshari, A.; Sayyed-Alangi, S.Z. Antioxidant effect of leaf extracts from Cressa cretica against oxidation process in soybean oil. Food Sci. Nutr. 2017, 5, 324-333. [CrossRef]

28. FDA. Food Additive Status List. 2020. Available online: https://www.fda.gov/food/food-additives-petitions/ food-additive-status-list (accessed on 14 July 2020).

29. Castro-López, C.; Ventura-Sobrevilla, J.M.; González-Hernández, M.D.; Rojas, R.; Ascacio-Valdés, J.A.; Aguilar, C.N.; Martínez-Ávila, G.C.C. Impact of extraction techniques on antioxidant capacities and phytochemical composition of polyphenol-rich extracts. Food Chem. 2017, 237, 1139-1148. [CrossRef]

30. Manzano, P.; Hernández, J.; Quijano-Avilés, M.; Barragán, A.; Chóez-Guaranda, I.; Viteri, R.; Valle, O. Polyphenols extracted from Theobroma cacao waste and its utility as antioxidant. Emir. J. Food Agric. 2017, 29,45-50. [CrossRef]

31. Banerjee, J.; Singh, R.; Vijayaraghavan, R.; MacFarlane, D.; Patti, A.F.; Arora, A. Bioactives from fruit processing wastes: Green approaches to valuable chemicals. Food Chem. 2017, 225, 10-22. [CrossRef]

32. Eggersdorfer, M.; Wyss, A. Carotenoids in human nutrition and health. Arch. Biochem. Biophys. 2018, 652, 18-26. [CrossRef] [PubMed]

33. Lafka, T.I.; Lazou, A.E.; Sinanoglou, V.J.; Lazos, E.S. Phenolic extracts from wild olive leaves and their potential as edible oils antioxidants. Foods 2013, 2, 18-31. [CrossRef] [PubMed]

34. Zeb, A.; Ullah, F. Effects of spinach leaf extracts on quality characteristics and phenolic profile of sunflower oil. Eur. J. Lipid Sci. Technol. 2019, 121, 1800325. [CrossRef]

35. Inoue, M.; Hayashi, S.; Craker, L.E. Role of medicinal and aromatic plants: Past, present, and future. In Pharmacognosy-Medicinal Plants; Intech Open: London, UK, 2019. [CrossRef]

36. Christaki, E.; Bonos, E.; Giannenas, I.; Florou-Paneri, P. Aromatic plants as a source of bioactive compounds. Agriculture 2012, 2, 228-243. [CrossRef]

37. Kozłowska, M.; Gruczyńska, E. Comparison of the oxidative stability of soybean and sunflower oils enriched with herbal plant extracts. Chem. Pap. 2018, 72, 2607-2615. [CrossRef]

38. Boroski, M.; Aguiar, A.C.; Rotta, E.M.; Bonafe, E.G.; Valderrama, P.; Souza, N.E.; Visentainer, J.V. Antioxidant activity of herbs and extracted phenolics from oregano in canola oil. Int. Food Res. J. 2018, 25, 2444-2452.

39. Phuong, N.N.M.; Le, T.T.; Nguyen, M.V.T.; Van Camp, J.; Raes, K. Antioxidant activity of rambutan (Nephelium lappaceum L.) peel extract in soybean oil during storage and deep frying. Eur. J. Lip. Sci. Technol. 2020, 122, 1900214. [CrossRef] 
40. Agregán, R.; Lorenzo, J.M.; Munekata, P.E.S.; Dominguez, R.; Carballo, J.; Franco, D. Assessment of the antioxidant activity of Bifurcaria bifurcata aqueous extract on canola oil. Effect of extract concentration on the oxidation stability and volatile compound generation during oil storage. Food Res. Int. 2017, 99, 1095-1102. [CrossRef]

41. Ajala, A.W.; Ghavami, A. Evaluation of the effectiveness of cereal bran extract for sunflower oil stability during frying. Int. J. Food Stud. 2020, 9, SI52-SI61. [CrossRef]

42. Giua, L.; Blasi, F.; Simonetti, M.S.; Cossignani, L. Oxidative modifications of conjugated and unconjugated linoleic acid during heating. Food Chem. 2013, 140, 680-685. [CrossRef]

43. Cossignani, L.; Giua, L.; Simonetti, M.S.; Blasi, F. Volatile compounds as indicators of conjugated and unconjugated linoleic acid thermal oxidation. Eur. J. Lipid Sci. Technol. 2014, 116, 407-412. [CrossRef]

44. Venturi, F.; Sanmartin, C.; Taglieri, I.; Nari, A.; Andrich, G.; Terzuoli, E.; Donnini, S.; Nicolella, C.; Zinnai, A. Development of phenol-enriched olive oil with phenolic compounds extracted from wastewater produced by physical refining. Nutrients 2017, 9, 916. [CrossRef] [PubMed]

45. El-Hamidi, M.; Zaher, F.A. Production of vegetable oils in the world and in Egypt: An overview. Bull. Nat. Res. Centre 2018, 42, 19. [CrossRef]

46. Günal-Köroğlu, D.; Turan, S.; Kiralan, M.; Ramadan, M.F. Enhancement of sunflower oil stability during deep-frying using extracts from olive oil by-products and soy lecithin. Int. Food Res. J. 2019, 26, 1269-1277.

47. Zeb, A.; Nisar, P. Effects of high temperature frying of spinach leaves in sunflower oil on carotenoids, chlorophylls, and tocopherol composition. Front. Chem. 2017, 5, 19. [CrossRef]

48. Hussain, S.A.; Hameed, A.; Ajmal, I.; Nosheen, S.; Rasul Suleria, H.A.; Song, Y. Effects of sesame seed extract as a natural antioxidant on the oxidative stability of sunflower oil. J. Food Sci. Technol. 2018, 55, 4099-4110. [CrossRef]

49. Blasi, F.; Pollini, L.; Cossignani, L. Varietal authentication of extra virgin olive oils by triacylglycerols and volatiles analysis. Foods 2019, 8, 58. [CrossRef]

50. Galanakis, C.M.; Tsatalas, P.; Charalambous, Z.; Galanakis, I.M. Polyphenols recovered from olive mill wastewater as natural preservatives in extra virgin olive oils and refined olive kernel oils. Environ. Technol. Innov. 2018, 10, 62-70. [CrossRef]

51. Nieva-Echevarría, B.; Goicoechea, E.; Guillén, M.D. Oxidative stability of extra-virgin olive oil enriched or not with lycopene. Importance of the initial quality of the oil for its performance during in vitro gastrointestinal digestion. Food Res. Int. 2020, 130, 108987. [CrossRef]

52. Roschel, G.G.; da Silveira, T.F.F.; Cajaiba, L.M.; Castro, I.A. Combination of hydrophilic or lipophilic natural compounds to improve the oxidative stability of flaxseed oil. Eur. J. Lipid Sci. Technol. 2019, 121, 1800459. [CrossRef]

53. Mohanan, A.; Nickerson, M.T.; Ghosh, S. Oxidative stability of flaxseed oil: Effect of hydrophilic, hydrophobic and intermediate polarity antioxidants. Food Chem. 2018, 266, 524-533. [CrossRef] [PubMed]

54. Asadi, Y.; Farahmandfar, R. Frying stability of canola oil supplemented with ultrasound-assisted extraction of Teucrium polium. Food Sci. Nutr. 2020, 8, 1187-1196. [CrossRef] [PubMed]

55. Gülmez, Ö.; Şahin, S. Evaluation of oxidative stability in hazelnut oil treated with several antioxidants: Kinetics and thermodynamics studies. LWT Food Sci. Technol. 2019, 111, 478-483. [CrossRef]

(C) 2020 by the authors. Licensee MDPI, Basel, Switzerland. This article is an open access article distributed under the terms and conditions of the Creative Commons Attribution (CC BY) license (http://creativecommons.org/licenses/by/4.0/). 